\title{
Surface Morphology of Single and Multi-Layer Silicon Nitride Dielectric Nano- Coatings on Silicon Dioxide and Polycrystalline Silicon
}

\section{Liga AVOTINA ${ }^{1}$, Elina PAJUSTE ${ }^{1}$, Marina ROMANOVA ${ }^{2}$, Gennady ENICHEK ${ }^{3}$, Aleksandrs ZASLAVSKIS ${ }^{3}$, Valentina KINERTE ${ }^{1}$, Juris AVOTINS ${ }^{1}$, Yuri DEKHTYAR ${ }^{2}$, Gunta KIZANE ${ }^{1}$}

\author{
${ }^{1}$ University of Latvia, Institute of Chemical Physics, Jelgavas str. 1, Riga, Latvia \\ ${ }^{2}$ Riga Technical University, Institute of Biomedical Engineering and Nanotechnologies, Viskalu Str. 36A, Riga, Latvia \\ ${ }^{3}$ Joint Stock Company, “ALFA RPAR”, Ropazu str.140, Riga, Latvia \\ crossref http://dx.doi.org/10.5755/j01.ms.26.1.21479
}

Received 20 August 2018; accepted 14 December 2018

\begin{abstract}
Silicon nitride $\left(\mathrm{Si}_{3} \mathrm{~N}_{4}\right)$ in a form of single and multi-layer nanofilms is proposed to be used as a dielectric layer in nanocapacitors for operation in harsh environmental conditions. Characterization of surface morphology, roughness and chemical bonds of the $\mathrm{Si}_{3} \mathrm{~N}_{4}$ coatings has an important role in production process as the surface morphology affects the contact surface with other components of the produced device. $\mathrm{Si}_{3} \mathrm{~N}_{4}$ was synthesized by using low pressure chemical vapour deposition method and depositing single and multi-layer (3 - 5 layers) nanofilms on $\mathrm{SiO}_{2}$ and polycrystalline silicon (PolySi). The total thickness of the synthesized nanofilms was $20-60 \mathrm{~nm}$. Surface morphology was investigated by means of scanning electron microscopy (SEM) and atomic force microscopy (AFM). Chemical bonds in the layers were identified by means of Fourier transform infrared spectrometry, attenuated total reflection (FTIR-ATR) method. (From the SEM and AFM images it was estimated that both single and multi-layer coatings are deposited homogenously. Si-N breathing and stretching modes are observed in FTIR spectra and the surface morphology is highly dependent on PolySi, therefore suggesting the decrease of the roughness of the bottom electrode for use in the nanocapacitors.

Keywords: silicon nitride, surface morphology, electron microscopy, atomic force microscopy.
\end{abstract}

\section{INTRODUCTION}

Silicon nitride $\left(\mathrm{Si}_{3} \mathrm{~N}_{4}\right)$ has a unique combination of electrical and mechanical properties: high dielectric constant, hardness and wear resistance, which are very advantageous under action of harsh conditions. It is proposed to use $\mathrm{Si}_{3} \mathrm{~N}_{4}$ in space technology under action of ionizing radiation [1], for sensing applications [2], in Li-ion batteries and solar applications [3-8].

The capacitance of a capacitor increases when thickness of the dielectric decreases. However, the thickness of the dielectric in nanocapacitors is limited due to inhomogeneities arising at nanoscale. Defects that are present in the dielectric nanolayer will have a great impact on its performance. Therefore, the control of deposition technology for obtaining homogeneous and defect-free dielectric nanolayers is of great importance.

$\mathrm{Si}_{3} \mathrm{~N}_{4}$ dielectric can be deposited as a single layer or as a multi-layer nanofilm. The main difference between the single layer and the multi-layer $\mathrm{Si}_{3} \mathrm{~N}_{4}$ lies in the interfaces between the individual $\mathrm{Si}_{3} \mathrm{~N}_{4}$ nano layers constituting the multi-layer film. The elemental composition at the interfaces differs from the bulk of the film, which can lead to changes in optical properties, breakdown voltage and leakage current characteristics of the multi-layer $\mathrm{Si}_{3} \mathrm{~N}_{4}$ compared to the single layer film [9]. Content of oxygen can change at the interfaces between the individual $\mathrm{Si}_{3} \mathrm{~N}_{4}$ nanolayers and this influences the formation of electrically active centres in the dielectric [10]. The multi-layer nanofilm is knows to have less pinholes compared to the single layer due to the fact that any pinholes present in an individual $\mathrm{Si}_{3} \mathrm{~N}_{4}$ nanolayer will be covered by the next $\mathrm{Si}_{3} \mathrm{~N}_{4}$ nanolayer during its deposition [9].

Characterization of surface morphology, roughness and chemical bonds of the $\mathrm{Si}_{3} \mathrm{~N}_{4}$ coatings is required in order to estimate differences between single and multi-layer $\mathrm{Si}_{3} \mathrm{~N}_{4}$ coatings. The surface morphology affects the contact surface with the other components of the produced device. By optimizing the synthesis conditions, it will be possible to improve the required properties according to the applications of the synthesized layers.

In this paper we investigate the chemical bonds and surface morphology of $\mathrm{Si}_{3} \mathrm{~N}_{4}$ single and multi-layer coatings 20-60 nm thickness on $\mathrm{SiO}_{2}$ and polycrystalline silicon (PolySi), in order to estimate differences between various synthesis parameters, two types of bottom electrode and to develop recommendations for producers.

\section{EXPERIMENTAL DETAILS}

The silicon nitride $\left(\mathrm{Si}_{3} \mathrm{~N}_{4}\right)$ layers were fabricated on the Si $(76 \mathrm{~mm})$ wafer (111 wafer surface). The wafer was oxidized at $1130{ }^{\circ} \mathrm{C}$ in the oxygen environment for 2 hours. The thickness of $\mathrm{SiO}_{2}$ was $1 \mu \mathrm{m}$. Polycrystalline Si layer (PolySi) was deposited on $\mathrm{SiO}_{2}$ as a bottom electrode of the nanocapacitor. The deposition of PolySi was performed in

\footnotetext{
* Corresponding author. Tel.: +371-67033937; fax: +371-67033937.

E-mail address: liga.avotina@lu.lv (L. Avotina)
} 
the atmosphere of $\mathrm{SiH}_{4}$ and $\mathrm{N}_{2}$ gases at $900{ }^{\circ} \mathrm{C}$ during 40 minutes. The thickness of PolySi was $0.4 \mu \mathrm{m}$. Deposition of the conductive polycrystalline $\mathrm{Si}$ layer was done in $\mathrm{SiH}_{4}$ and $\mathrm{N}_{2}$ gases atmosphere during 40 minutes at $900{ }^{\circ} \mathrm{C}$, the layer was doped with phosphorus (gases: $\mathrm{POCl}_{3}, \mathrm{O}_{2}+\mathrm{N}_{2}$; 15 minutes; $900{ }^{\circ} \mathrm{C}$ ); a thickness of the layer was $0.4 \mu \mathrm{m}$. $\mathrm{Si}_{3} \mathrm{~N}_{4}$ dielectric nanolayer was deposited on the PolySi electrode using Low Pressure Chemical Vapour Deposition (LPCVD). $\mathrm{Si}_{3} \mathrm{~N}_{4}$ was synthesized performing a reaction: $\mathrm{SiH}_{4}+\mathrm{NH}_{3}$ at $800{ }^{\circ} \mathrm{C}$, achieving the single or multi-layer coating. The multi-layer coating consisted of several $\mathrm{Si}_{3} \mathrm{~N}_{4}$ nanolayers. To fabricate $\mathrm{Si}_{3} \mathrm{~N}_{4}$ multi-layer, the inflow of $\mathrm{SiH}_{4}$ was stopped after the deposition of the first $\mathrm{Si}_{3} \mathrm{~N}_{4}$ nanolayer, and its surface was annealed in a $\mathrm{NH}_{3}$ stream at $800{ }^{\circ} \mathrm{C}$ for 10 minutes. After the annealing, deposition of the next $\mathrm{Si}_{3} \mathrm{~N}_{4}$ nanolayer was performed. The process of the deposition and annealing was repeated several times to obtain desired number of $\mathrm{Si}_{3} \mathrm{~N}_{4}$ nanolayers. Several types of the $\mathrm{Si}_{3} \mathrm{~N}_{4}$ coatings were synthesized: 20 and $25 \mathrm{~nm}$ single (assigned as $1 \times$ ) and 3 layered $(3 \times)$ coatings, 40 and $60 \mathrm{~nm}$ single $(1 \times)$ and 5 layered $(5 \times)$ coatings.

The surface morphology of single and multi-layer coatings was measured by SEM (field emission scanning electron microscope Hitachi S-4800) and AFM (Asylum Research MFP-3D atomic force microscope). AFM imaging was performed in tapping mode using NT-MDT NSG10 probes. The roughness parameters $R \mathrm{a}$ and $R \mathrm{q}$ were calculated from AFM images with a scan size $3 \times 3 \mu \mathrm{m}$ and $256 \times 256$ data points using Igor Pro software according to Eq. 1 and Eq. 2:

$R a=\frac{1}{N} \sum_{i=1}^{N}\left|Z_{i}-\bar{Z}\right|$

$R q=\sqrt{\frac{1}{N-1} \sum_{i=1}^{N}\left(Z_{i}-\bar{Z}\right)^{2}}$,

where $Z_{i}$ is the height at a given pixel $i, N$ is the total number of pixels in the image, $\bar{Z}$ is the average height of the entire image.

The Fourier transform infrared (FTIR) spectra were recorded with Bruker Vertex 70v spectrometer - equipped with an attenuated total reflection (ATR) module that contains a diamond crystal with refractive index 2.4. The spectra were recorded in a spectral range of $4000-400 \mathrm{~cm}^{-1}$, in vacuum $2.95 \mathrm{hPa}$, resolution $\pm 2 \mathrm{~cm}^{-1}$, 20 scans per measurement.

\section{RESULTS AND DISCUSSION}

\subsection{Characterisation of surface chemical bonds}

The 20-60 nm single and multi-layer $\mathrm{Si}_{3} \mathrm{~N}_{4}$ coatings were analysed with means of infrared spectrometry, attenuated total reflection. The samples were analysed prior and after deposition of each layer. The silicon substrate gives a signal around $510 \mathrm{~cm}^{-1}$. By depositing $\mathrm{SiO}_{2}$, the $\mathrm{Si}$ signal does not occur in the spectrum and intensive signals of Si-O streching, bending and rocking occur [3]. By covering the $\mathrm{SiO}_{2}$ the PolySi layer doped with phosphorous, $\mathrm{Si}-\mathrm{O}$ bonds, the intensity of $\mathrm{Si}-\mathrm{O}$ bonds significantly decreases. In the spectrum of the $\mathrm{Si}_{3} \mathrm{~N}_{4}$ single and multilayer coatings on the PolySi the main bonds occur in the range of $400-1300 \mathrm{~cm}^{-1}$.

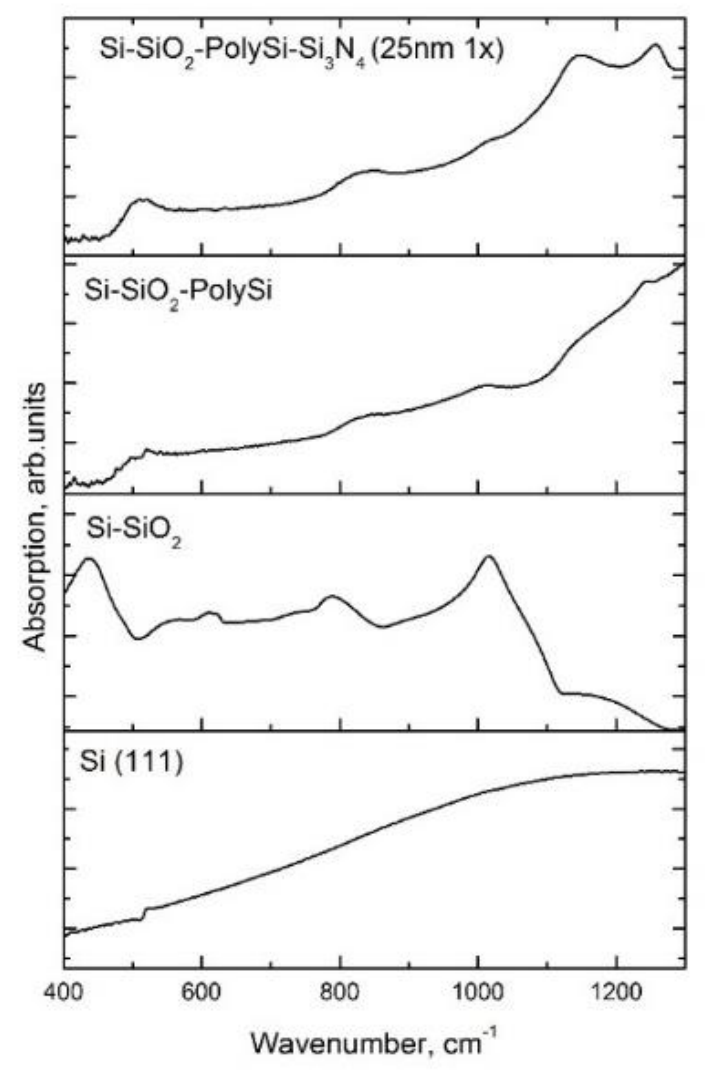

Fig. 1. FTIR spectra of (from bottom to top) Si substrate, Si coated with $\mathrm{SiO}_{2}, \mathrm{Si}$ coated with $\mathrm{SiO}_{2}$ and PolySi doped with $\mathrm{P}, \mathrm{Si}$ coated with $\mathrm{SiO}_{2}$, PolySi doped with $\mathrm{P}$ and coated with single layer $\mathrm{Si}_{3} \mathrm{~N}_{4}$

The FTIR spectra of the each deposited coating are presented in Fig. 1.

In Fig. 1, where $\mathrm{Si}_{3} \mathrm{~N}_{4}$ coating is deposited, a signal around $490-530 \mathrm{~cm}^{-1}$ could be due to Si-N breathing [11] and $\mathrm{Si}-\mathrm{N}$ stretching mode [12].

The signal at $840 \mathrm{~cm}^{-1}$ is due do Si-N bonds [13], while at $1000-1100 \mathrm{~cm}^{-1}$ the signals occur due to Si-N stretching $[7,13]$ and presence of Si-O-N [11].

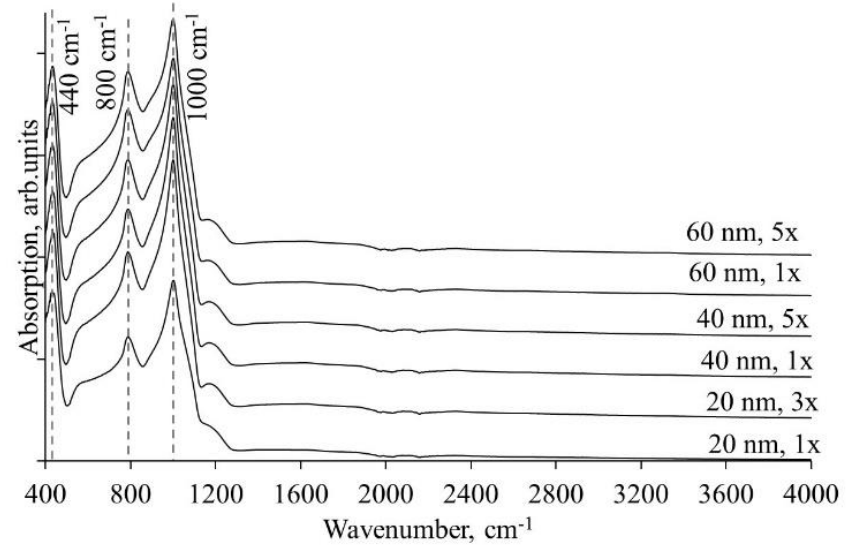

Fig. 2. FTIR spectra of deposited $\mathrm{Si}_{3} \mathrm{~N}_{4}$ single and multi-layer coatings on the $\mathrm{Si}$ substrate covered with $\mathrm{SiO}_{2}$

FTIR spectra of the $\mathrm{Si}_{3} \mathrm{~N}_{4}$ coatings on the surface of $\mathrm{SiO}_{2}$ are presented in Fig. 2. The multiplication sign in the description of the spectrum shows the number of individual $\mathrm{Si}_{3} \mathrm{~N}_{4}$ nanolayers in the particular coating. In the spectra 
strong signals of the $\mathrm{Si}-\mathrm{O}$ bonds are timed. The $\mathrm{Si}-\mathrm{N}$ bonds are not clearly visible. To determine the influence of the synthesis method and the number of $\mathrm{Si}-\mathrm{N}$ layers on the chemical composition of the surface, the FTIR spectra of the $\mathrm{Si}_{3} \mathrm{~N}_{4}$ coatings were analysed. The main signals occur in the range of $900-1200 \mathrm{~cm}^{-1}$ and they are due $\mathrm{Si}-\mathrm{N}$ bonds. Spectral distortions that occur in the range of $1900-2300 \mathrm{~cm}^{-1}[15]$ are probably due to the similar values of refractive indices of the diamond crystal and the synthesized $\mathrm{Si}_{3} \mathrm{~N}_{4}$. The FTIR spectra of the $\mathrm{Si}_{3} \mathrm{~N}_{4}$ coatings on the PolySi are presented in Fig. 3. In the FTIR spectra the $\mathrm{Si}-\mathrm{N}$ signal intensities are similar in both cases, single and multi-layer $\mathrm{Si}_{3} \mathrm{~N}_{4}$ coatings.

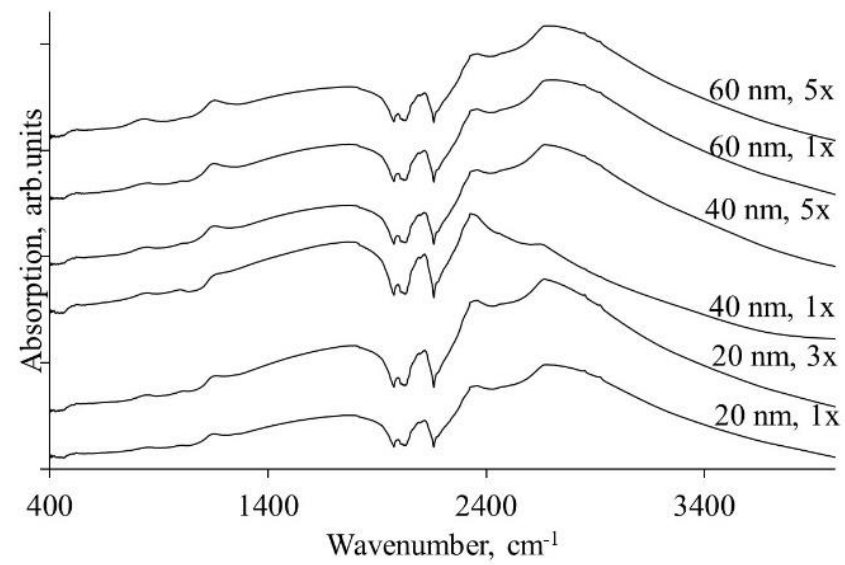

Fig. 3. FTIR spectra of deposited layers on the Si substrate covered with $\mathrm{SiO}_{2}$ and PolySi doped with $\mathrm{P}$

To compare the morphology of the single and multilayer $\mathrm{Si}_{3} \mathrm{~N}_{4}$ coatings, SEM and AFM measurements were performed. AFM image of PolySi deposited on $\mathrm{SiO}_{2}$ shows that the PolySi has a relatively rough surface (Fig. 4).

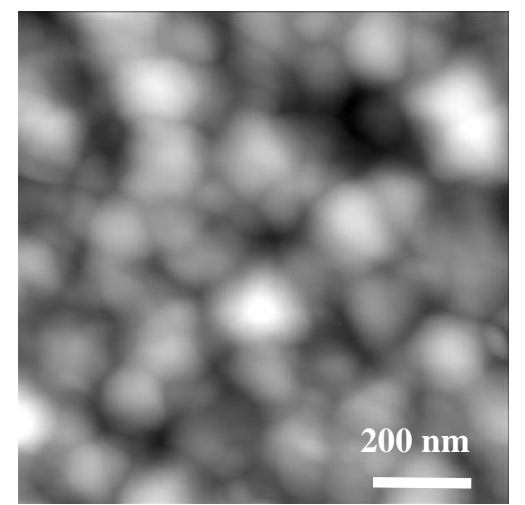

Fig. 4. AFM image of a PolySi on the $\mathrm{Si}$ covered with $\mathrm{SiO}_{2}$

SEM images of the single and multi-layer $\mathrm{Si}_{3} \mathrm{~N}_{4}$ coatings deposited on PolySi are shown Fig. 5a and Fig. 5b respectively. The fine grains of $\mathrm{Si}_{3} \mathrm{~N}_{4}$ homogeneously and fully cover the bigger bumps formed by PolySi, no pinholes to the PolySi surface were observed. The size of $\mathrm{Si}_{3} \mathrm{~N}_{4}$ grains obtained from the SEM measurements is in the range of $15-40 \mathrm{~nm}$ for both the single layer and multi-layer coatings.

SEM and AFM measurements demonstrated that the total thickness of $\mathrm{Si}_{3} \mathrm{~N}_{4}$ dielectric and number of individual $\mathrm{Si}_{3} \mathrm{~N}_{4}$ nanolayers do not influence surface morphology of
$\mathrm{Si}_{3} \mathrm{~N}_{4}$. However, the surface morphology is determined by the underlying layer. Height profiles of $\mathrm{SiO}_{2}$, PolySi layers and $\mathrm{Si}_{3} \mathrm{~N}_{4}$ layers deposited either on PolySi or $\mathrm{SiO}_{2}$ were extracted from AFM images (Fig. 6).

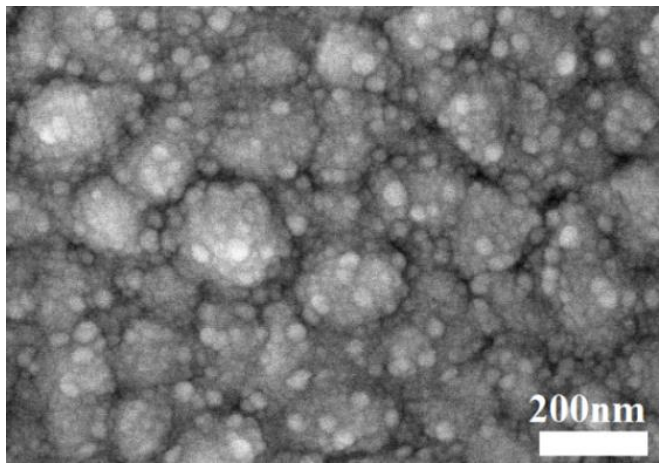

a

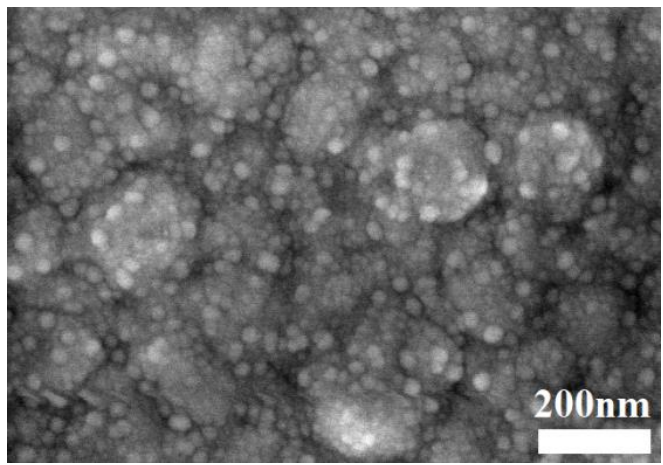

$\mathrm{b}$

Fig. 5. SEM image of a $40 \mathrm{~nm}$ thick $\mathrm{Si}_{3} \mathrm{~N}_{4}$ nanolayer deposited on PolySi: $a$-single layer; $b$ - multi-layer

The height profiles of PolySi and $\mathrm{Si}_{3} \mathrm{~N}_{4}$ deposited on PolySi are similar, having bumps with heights around 10-20 nm. The height profile of $\mathrm{Si}_{3} \mathrm{~N}_{4}$ deposited on a relatively smooth $\mathrm{SiO}_{2}$ shows little bumps with heights in the range of $1-3 \mathrm{~nm}$. Fig. 7 shows the roughness parameters $\mathrm{Ra}$ and $\mathrm{Rq}$ measured for each layer of the $\mathrm{Si}$ $\mathrm{SiO}_{2}-\mathrm{PolySi}_{-} \mathrm{Si}_{3} \mathrm{~N}_{4}$ structure. In the case of $\mathrm{SiO}_{2}$ as the underlying layer with $R \mathrm{a}=151 \mathrm{pm}(R \mathrm{q}=201 \mathrm{pm}), R \mathrm{a}$ of $\mathrm{Si}_{3} \mathrm{~N}_{4}$ is $1.2 \pm 0.1 \mathrm{~nm}(R \mathrm{q}=1.4 \pm 0.1 \mathrm{~nm})$. In the case of PolySi as the underlying layer with $R \mathrm{a}=8.7 \mathrm{~nm}$ $(R \mathrm{q}=11.0 \mathrm{~nm}), \quad R \mathrm{a} \quad$ of $\quad \mathrm{Si}_{3} \mathrm{~N}_{4} \quad$ is $\quad 8.5 \pm 0.3 \mathrm{~nm}$ $(R \mathrm{q}=10.5 \pm 0.4 \mathrm{~nm})$.

The morphology measurements demonstrated that when PolySi is used as a bottom electrode of a nanocapacitor, the surface morphology of $\mathrm{Si}_{3} \mathrm{~N}_{4}$ dielectric is determined by PolySi. In this case the roughness of $\mathrm{Si}_{3} \mathrm{~N}_{4}$ is comparable with the total thickness of the dielectric. This is undesirable for nanocapacitors, since it causes dielectric breakdowns at high voltages and increases leakage currents due to the local amplification of the electric field at surface peaks and changes in the local thickness of the dielectric between two adjacent electrodes [15]. This means that controlling the roughness of the bottom electrode plays a critical role in nanocapacitors. The roughness of the bottom electrode should be minimized either by selecting the appropriate electrode material or by adjusting the deposition technology. 

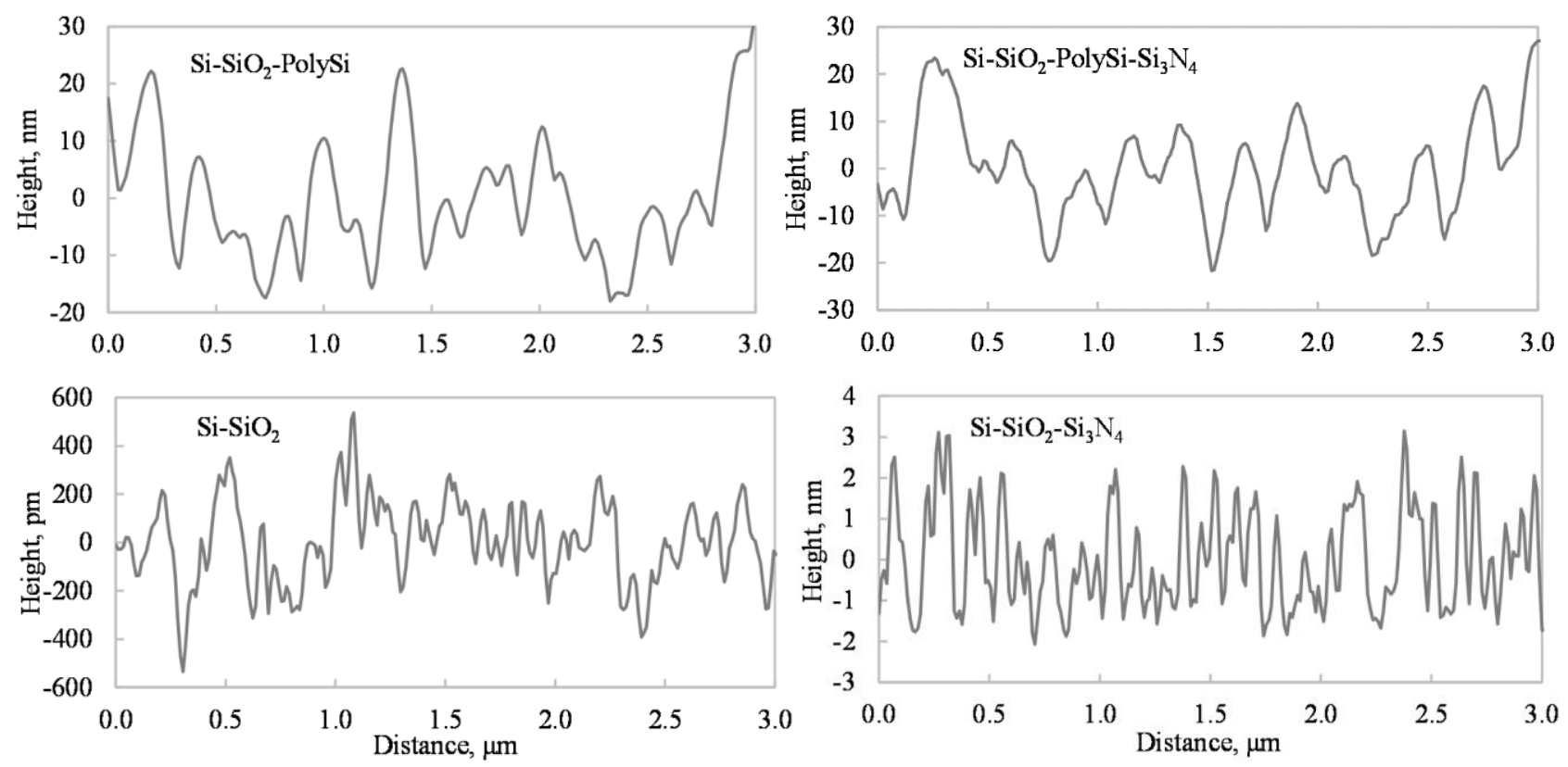

Fig. 6. Height profiles of $\mathrm{SiO}_{2}$, PolySi layer and $\mathrm{Si}_{3} \mathrm{~N}_{4}$ nanolayer deposited either on $\mathrm{PolySi}_{\text {or }} \mathrm{SiO}_{2}$

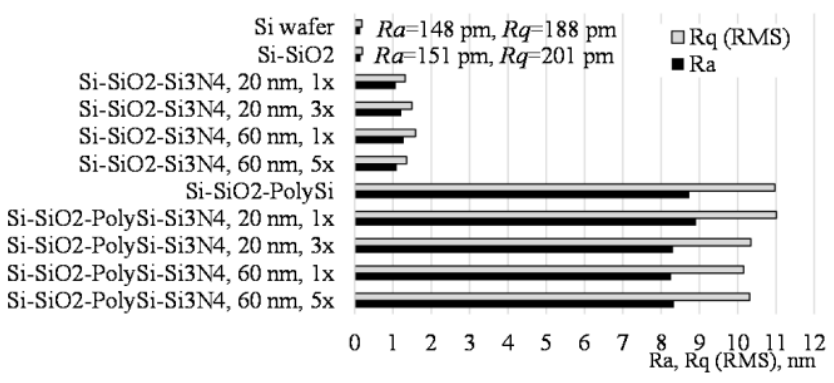

Fig. 7. Roughness parameters $R a$ and $R q$ of $\mathrm{Si}$ wafer, $\mathrm{SiO}_{2}$, PolySi layers and $\mathrm{Si}_{3} \mathrm{~N}_{4}$ nanolayers deposited either on PolySi or $\mathrm{SiO}_{2}$ layer

\section{CONCLUSIONS}

Si-N breathing and stretching modes are observed in the FTIR spectra of deposited layers, however in the case, where $\mathrm{Si}_{3} \mathrm{~N}_{4}$ is deposited on the top of $\mathrm{SiO}_{2}$, the $\mathrm{SiO}_{2}$ bonds are dominant.

The surface roughness and morphology of $20-60 \mathrm{~nm}$ thick single and multi-layer $\mathrm{Si}_{3} \mathrm{~N}_{4}$ coatings deposited by LPCVD are similar. The sizes of $\mathrm{Si}_{3} \mathrm{~N}_{4}$ grains are in the range of $15-40 \mathrm{~nm}$. The coatings are deposited homogenously over the underlying layer and no pinholes to the underlying layer are observed.

In the case of a nano thick $\mathrm{Si}_{3} \mathrm{~N}_{4}$ dielectric, its surface morphology and roughness is highly dependent on the roughness of the underlying layer. Therefore, the choice of the appropriate material of the bottom electrode for use in nanocapacitors is very important. The roughness of the bottom electrode has to be less or similar to the roughness of $\mathrm{Si}_{3} \mathrm{~N}_{4}$. The roughness of PolySi as the bottom electrode was comparable to the thickness of $\mathrm{Si}_{3} \mathrm{~N}_{4}$, which is undesirable as it increases the probability of dielectric breakdown at high voltages and increases leakage currents. The roughness of the bottom electrode should be minimized either by selecting the appropriate electrode material or by adjusting the deposition technology.

\section{Acknowledgments}

The research was supported by European Regional Development Fund Project No.1.1.1.1/16/A/203 "Multilayer silicon nanocapacitor with improved dielectric layers".

\section{REFERENCES}

1. Li, D., Li, B., Yang, X., Gao, S., Zheng, Y. Fabrication and Properties of In Situ Silicon Nitride Nanowires Reinforced Porous Silicon Nitride (SNNWS/SN) Composites Journal of the European Ceramic Society 38 2018: pp. 2671-2675. https://doi.org/10.1016/j.jeurceramsoc.2018.02.001

2. Hoi, H., Rezaie, S.S., Gong, L., Sen, P., Zeng, H., Montemagno, C., Gupta, M. Biofunctionalized Silicon Nitride Platform for Sensing Applications Biosensors and Bioelectronics 102 2018: pp. 497-503. https://doi.org/10.1016/j.bios.2017.11.059

3. Riley, F.L. Silicon Nitride and Related Materials Journal of the American Ceramic Society 83 (2) 2000: pp. 245-265.

4. Anh Pham, T., Li, T., Shankar, S., Gygi, F., Galli, G. FirstPrinciples Investigations of the Dielectric Properties of Crystalline and Amorphous $\mathrm{Si}_{3} \mathrm{~N}_{4}$ Thin Films Applied Physics Letters 96 (062902) 2010: pp. 1-3.

5. Steffens, J., Fazio, M.A., Cavalcoli, D., Terheiden, B. Multi-Characterization Study of Interface Passivation Quality of Amorphous Sub-Stoichiometric Silicon Oxide and Silicon Oxynitride Layers for Photovoltaic Applications Solar Energy Materials and Solar Cells 187 2018: pp. 104-112. https://doi.org/10.106.j.solmat.2018.07.024

6. Ulvestad, A., Andersen, H.F., Jensen, I.J.T., Monstad, T.T., Maehlen, J.P., Prytz, O., Kirkengen, M. Substoichiometric Silicon Nitride - An Anode Material for Li-ion Batteries Promising High Stability and High Capacity Scientific Reports 8 (8634) 2018: pp. 1-13. https://doi.org/10.1038/s4169869-018-26769-8 
7. Tiron, V., Velicu, I.L., Pana, I., Cristea, D., Rusu, B.G., Dinca, P., Porosnicu, C., Grigore, E., Munteanu, D., Tascu, S. HiPIMS Deposition of Silicon Nitride for Solar Cell Application Surface and Coatings Technology 344 2018: pp. 197-203. https://doi.org/10.1016/j.surfcoat.2018.03.025

8. Dekkers, H.F.W., De Wolf, S., Agostinelli, G., Duerinckx, F., Beaucarne, G. Requirements of PECVD SiNx:H Layers for Bulk Passivation of mc-Si Solar Energy Materials and Solar Cells $90(19-19)$ 2006: pp. $3244-3250$. https://doi.org/10.1016/j.solmat.2006.06.024

9. Yota, J. Effects of Deposition Method of PECVD Silicon Nitride as MIM Capacitor Dielectric for GaAs HBT Technology ECS Transactions 35 (4) 2011: pp. 229-240.

10. Dekhtyar, Yu., Avotina, L., Enichek, G., Romanova, M., Schmidt, B., Shulzinger, E., Sokokins, H., Vilken, A., Zaslavski, A. Interface of Silicon Nitride Nanolayers with Oxygen Deficiency Proceedings of the 16th Biennial Baltic Electronics Conference (BEC2018) Tallinn, Estonia, October 2018: pp. 8-10.

11. Cianci, E., Schina, A., Minotti, A., Quaresima, S., Foglietti, V. Dual Frequency PECVD Silicon Nitride for
Fabrication of CMUT's Membranes Sensors and Actuators A 127 2008: pp. 80-87.

https://doi.org/10.1016/j.sna.2008.11.053

12. Scradera, G., Puzzer, T., Conibeer, G., Green, M.A. Fourier Transform Infrared Spectroscopy of Annealed Silicon-Rich Silicon Nitride Thin Films Journal of Applied Physics 104 (104310) 2008: pp. 1-8. https://doi.org/10.1063/1.3021158

13. Walsh, L.A., Mohammed, S., Sampat, S.C., Chabal, Y.J., Malko, A.V., Hinkle, C.L. Oxide-Related Defects in Quantum Dot Containing Si-Rich Silicon Nitride Films Thin Solid Films 636 2017: pp. 267-272. http://dx.doi.org/10.1016/j.tsf.2017.06.022

14. Mastalerz, M., Bustin, R.M. Application of Reflectance Micro-Fourier Transform Infrared Spectrometry in Studying Coal Macerals: Comparison with Other Fourier Transform Infrared Techniques Fuel 74 (4) 1995: pp. 536-542.

15. Samantaray, M.M., Gurav, A., Dickey, E.C., Randall, C.A. Electrode Defects in Multilayer Capacitors Part I: Modeling the Effect of Electrode Roughness and Porosity on Electric Field Enhancement and Leakage Current Journal of the American Ceramic Society 95 (1) 2012: pp. 257-263. 